\title{
Is Vitamin D Level Elevated in Patients on Statin Treatment?
}

\author{
Gulcin Sahingoz Erdal, Nihan Turhan Caglar', Dilay Karabulut', Nursel Kocamaz, Nilgun Isiksacan² \\ Departments of Internal Medicine, ${ }^{1}$ Cardiology and ${ }^{2}$ Biochemistry, Bakirkoy Dr. Sadi Konuk Training and Research Hospital, Istanbul, Turkey \\ ORCID: \\ Gulcin Sahingoz Erdal: https://orcid.org/0000-0001-5815-5847 \\ Nihan Turhan Caglar: https://orcid.org/0000-0001-7925-2398 \\ Dilay Karabulut: https://orcid.org/0000-0003-1896-0096 \\ Nursel Kocamaz: https://orcid.org/0000-0003-3489-2329 \\ Nilgun Isiksacan: https://orcid.org/0000-0002-0230-6500
}

\section{Abstract}

Context: Statins are effective agents on both primary and secondary prevention in patients who are at high risk of cardiovascular disease, and the number of patients taking statins has significantly raised recently. Aims: The aim of this study was to evaluate the association between Vitamin D levels and statin usage, statin type, dose, and duration. Settings and Design: We enrolled 210 control and 174 patients who were taking statins, and whose Vitamin D levels were checked in the past 3 months. 25-hydroxy Vitamin D levels were analyzed by immunoassay. Subgroup analysis was done firstly according to statin types and other lipid-lowering agents, namely fenofibrate. Subjects and Methods: Statin dosage's effect on Vitamin D levels were analyzed in patients taking low-dose (10-20 mg/day) and high-dose (40-80 mg/day) atorvastatin. Patients were divided into three groups according to statin usage duration (short term: $>1$ month, less than a year, medium-term: 1-5 years, long term: > 5 years). Statistical Analysis Used: Kolmogorov-Smirnov, Kruskal-Wallis, Bonferroni Dunn's multiple comparisons, Spearman rank tests were used. Results: About $71.26 \%$ of the patient group was using atorvastatin, $13.21 \%$ rosuvastatin, $4.59 \%$ pitavastatin, and $10.91 \%$ were on fenofibrate treatment. Vitamin D levels were statistically different among statin subtypes $(P<0.001)$; the highest level was observed in patients taking atorvastatin $(23.03 \pm 9.94)$. Vitamin D levels were statistically significantly higher in short-term and medium-term statin usage than control group $(P<0.001)$. Conclusions: Our study demonstrated that even low-dose statin has a positive effect on Vitamin D. Thereby, it encourages patients to continue with statin therapy more willingly.

Keywords: Cardiovascular disease, statin, Vitamin D

\section{INTRODUCTION}

Statins are effective agents on both primary and secondary prevention in patients who are at high risk of cardiovascular disease (CVD) ${ }^{[1-4]}$ Recently, published articles reveal that statins prevent major cardiovascular events including all-cause mortality, cardiovascular mortality, morbidity, repeating cardiovascular events, and ischemic stroke in patients who have CVD ${ }^{[5-8]}$ Hence, the number of patients taking statins has significantly raised recently, and this upward trend will continue upon the rising number of high-risk patients and the aging population..$^{[9-11]}$

7-dehydrocholesterol (7-DHC) is the precursor of both Vitamin D and cholesterol in mammal tissues;

Submission: 06-Aug-19 Revision: 03-Sep-19 Accepted: 23-Sep-19

Published Online: 25-Nov-19

\begin{tabular}{|l|l|}
\hline \multicolumn{2}{c|}{ Access this article online } \\
\hline Quick Response Code: & Website: \\
& \\
http://www.ijcva.com
\end{tabular}

therefore, statins are expected to affect their metabolism. ${ }^{[12]}$ Statins diminish production of cholesterol and Vitamin D by reducing 7-DHC; however, there are some studies demonstrating higher serum Vitamin D levels in statin users. ${ }^{[13,14]}$ Moreover, there are few researches aligning no correlation between statins and Vitamin D levels in the literature. ${ }^{[15-17]}$

Our aim in this retrospective cross-sectional study was to evaluate the association between Vitamin D levels and statin usage, group, dose, and duration.

Address for correspondence: Dr. Nihan Turhan Caglar, Department of Cardiology, Bakirkoy Dr. Sadi Konuk Training and Research Hospital, Istanbul, Turkey. E-mail: nhnturhan@gmail.com

This is an open access journal, and articles are distributed under the terms of the Creative Commons Attribution-NonCommercial-ShareAlike 4.0 License, which allows others to remix, tweak, and build upon the work non-commercially, as long as appropriate credit is given and the new creations are licensed under the identical terms.

For reprints contact: reprints@medknow.com

How to cite this article: Erdal GS, Caglar NT, Karabulut D, Kocamaz N, Isiksacan N. Is Vitamin D level elevated in patients on statin treatment? Int J Cardiovasc Acad 2019;5:159-62. 


\section{Subjects and Methods}

This study was conducted in cardiology and internal medicine outpatient clinics of the hospital between March 2018 and March 2019. Ethical approval was obtained from Local Ethical Committees of the hospital (2018/427).

We enrolled patients who were taking statins, and whose Vitamin D levels were checked in the past 3 months. The control group was consisted of age- and sex-matched patients who were not using statins.

Patients who had Vitamin D replacement in the past 6 months, under treatment which might effect Vitamin D levels, chronic renal failure, malabsorption syndrome, pregnancy, malignancy, under the age of 18 years, and not capable of giving an informed consent were excluded from the study. Seasonal effects on Vitamin D levels were also taken into account; therefore, the patient and control group was balanced on seasons.

Subgroup analysis was done first according to statin subtypes and other lipid-lowering agents, namely fenofibrate. Statin dosage's effect on Vitamin D levels was analyzed in patients taking low-dose (10-20 mg/day) and high-dose (40-80 mg/day) atorvastatin. Besides, patients were divided into three groups according to statin usage duration (short term: $>1$ month, less than a year, medium term: $1-5$ years, long term: $>5$ years).

Venous blood samples were collected from patients after $12 \mathrm{~h}$ of starvation. Each serum sample was aliquoted into two tubes after centrifuge at $1400 \mathrm{rcf}$ for $10 \mathrm{~min}$, and stored at $-80^{\circ} \mathrm{C}$ until it could be analyzed for 25-hydroxy Vitamin D (25[OH] D). Serum $25(\mathrm{OH})$ D concentrations were analyzed using Beckman Coulter, UniCel DxI800 Immunoassay analyzer (Beckman Coulter Inc, U.S.A.) device by immunoassay method.

Number Cruncher Statistical System (NCSS) 11 (NCSS, 2017 Statistical Software) program was used for statistical analysis. Categorical variables were defined by frequency and percentage values. Continues variables were defined by mean, standard deviation, median, minimum, and maximum values. Normal distribution of continuous variables was analyzed by Kolmogorov-Smirnov test. Nonnormally distributed variables were analyzed using Kruskal-Wallis test. Bonferroni Dunn multiple comparison tests was used to determine the source of significance difference among groups with more than two variables. Spearman rank test was employed to analyze correlations among numeric variables. Statistical significance was accepted as $P<0.05$.

\section{RESULTS}

A total of 384 patients (210 control group) were included in the study. Totally, the mean age was $61.01 \pm 12.21$, and $57.92 \%(n=223)$ were female.

About $71.26 \%$ of the patients group was using atorvastatin, $13.21 \%$ rosuvastatin, $4.59 \%$ pitavastatin, and $10.91 \%$ was on fenofibrate treatment [Table 1]. Patients Vitamin D level was statistically higher than control group $(P<0.001)$. Vitamin D levels were statistically different among statin subtypes $(P<0.001)$, when the pitavastatin data excluded due to the number of patients, the highest level was observed in patients taking atorvastatin $(23.03 \pm 9.94)$ [Table 1]. In order to find the source of this difference Bonferroni Dunn's multiple comparison tests was applied for statin subtype dosage, duration, and Vitamin D levels. Overall, Vitamin D levels were statistically significantly higher in short-term and medium-term statin usage than control group $(P=0.002, P<0.001)$ [Table 2]. On the other hand, Vitamin D levels were similar among different atorvastatin and rosuvastatin doses and duration [Table 3]. Vitamin D levels were not different among low-dose $(10 \mathrm{mg} / \mathrm{d})$ and high-dose $(20 \mathrm{mg} / \mathrm{d})$ rosuvastatin short, medium, and long-term usage $(P>0.05)$ [Table 4]. Pitavastatin dosage and duration was not evaluated due to few numbers of patients on pitavastatin treatment.

\section{Discussion}

Our study demonstrated that Vitamin D levels are significantly elevated in patients taking atorvastatin $(P<0.001)$. This finding

\begin{tabular}{lcc}
\hline \begin{tabular}{l} 
Table 1: Vitamin D levels according to cholesterol drugs \\
and control group \\
\multicolumn{3}{c}{ Vitamin D ( $\boldsymbol{n}$ ) Mean. \pm SD Med. } \\
(Min.-Max.)
\end{tabular} \\
\hline \multicolumn{3}{c}{$\boldsymbol{P}$} \\
\hline $\begin{array}{l}\text { Cholesterol drugs } \\
\text { Atorvastatin }\end{array}$ & $(n=124) \% 71.26,23.03 \pm 9.94,22-(6-59)$ & $P<0.001$ \\
$\begin{array}{l}\text { Rosuvastatin } \\
\text { Pitavastatin }\end{array}$ & $(n=23) \% 13,21,21.52 \pm 7.83,21-(6-42)$ & \\
Fenofibrate & $(n=8) \% 04,59,24.5 \pm 12.82,23-(5-50)$ \\
Control group & $(n=210), 18.14 \pm 10.21,16-(3-65)$ \\
\hline
\end{tabular}

\begin{tabular}{lcc}
\hline \multicolumn{2}{c}{ Table 2: Vitamin D levels due to statin usage duration } \\
\hline & $\begin{array}{c}\text { Vitamin D }(\boldsymbol{n}) \text { Mean } \pm \text { SD } \\
\text { Med. (Min.-Max.) }\end{array}$ \\
\hline Statin Duration & $\boldsymbol{P}$ \\
$\quad$ Short term ( $\leq 1$ year $)$ & $(n=92), 22.34 \pm 10,3,21-(5-59)$ & $P<0.001$ \\
Medium term (2-5 year) & $(n=47), 23.58 \pm 8.03,23-(8-46)$ & \\
Long term ( $\geq 6$ years $)$ & $(n=31), 21.19 \pm 11.03,19-(6-52)$ \\
$\quad$ Control group & $(n=210), 18.22 \pm 10.13,16-(3-65)$ \\
\hline
\end{tabular}
Kruskall Wallis H testi

\begin{tabular}{lcc}
\hline $\begin{array}{l}\text { Table 3: Vitamin D levels in atorvastatin users, due to } \\
\text { dosage and duration }\end{array}$ & $\begin{array}{c}\text { Vitamin D, (n); mean } \pm \text { SD; } \\
\text { median (minimum-maximum) }\end{array}$ & $\boldsymbol{P}$ \\
\hline Atorvastatin & $(41) ; 22.46 \pm 8.62 ; 22(9-44)$ & $>0.05$ \\
& $(31) ; 24.43 \pm 8 ; 24(12-46)$ & $>0.05$ \\
\hline Low-dose atorvastatin (years) & $(15) ; 23.93 \pm 10.84 ; 21(8-46)$ & $>0.05$ \\
Short term $(\leq 1)$ & & \\
Medium term $(2-5)$ & $(19) ; 24 \pm 12.95 ; 22(8-59)$ & $>0.05$ \\
Long term $(\geq 6)$ & $(5) ; 24.2 \pm 9.78 ; 23(13-40)$ & $>0.05$ \\
High-dose atorvastatin (years) & $(10) ; 17.8 \pm 13.5 ; 14.5(6-52)$ & $>0.05$ \\
\hline $\begin{array}{l}\text { Short term }(\leq 1) \\
\text { Medium term }(2-5)\end{array}$ & \\
\hline
\end{tabular}

Kruskal-Wallis H test. SD: Standard deviation 


\begin{tabular}{lcc}
\hline $\begin{array}{l}\text { Table 4: Vitamin D levels in rosuvastatin users, due to } \\
\text { dosage and duration }\end{array}$ & \\
\hline Rosuvastatin & $\begin{array}{c}\text { Vitamin D, }(\boldsymbol{n}) ; \text { mean } \pm \text { SD; } \\
\text { median (minimum-maximum) }\end{array}$ & $\boldsymbol{P}$ \\
\hline $\begin{array}{l}\text { Low-dose rosuvastatin (years) } \\
\text { Medium term (2-5) }\end{array}$ & $(4) ; 23 \pm 5.42 ; 25(15-27)$ & $>0.05$ \\
Long term ( $\geq 6)$ & $(2) ; 19.5 \pm 9.19 ; 19.5(13-26)$ & \\
High-dose rosuvastatin (years) & $(5) ; 20.4 \pm 13.39 ; 19(6-42)$ & $>0.05$ \\
Short term $(\leq 1)$ & $(4) ; 23.75 \pm 9 ; 22(16-35)$ & $>0.05$ \\
Medium term $(2-5)$ & $(4) ; 23.75 \pm 9 ; 22(16-35)$ & $>0.05$ \\
\hline Long term $(\geq 6)$ &
\end{tabular}

is correlated with the findings of Yavuz et al. ${ }^{[13]}$ They also revealed higher 25(OH) D and 1, 25-dihydroxy Vitamin D3 $(1,25[\mathrm{OH}] 2 \mathrm{D} 3)$ in patients under rosuvastatin and atorvastatin treatment. ${ }^{[13]}$ Meanwhile, Ertugrul et al. showed raised $25(\mathrm{OH})$ $\mathrm{D}$ levels with rosuvastatin, whilst fluvastatin was not associated with $25(\mathrm{OH}) \mathrm{D}^{\left[{ }^{[18]}\right.}$ On the other hand, although there were few patients in pitavastatin group, Vitamin D was high in all kinds of statin subgroups. Similarly, there are plenty of studies demonstrating an elevation in Vitamin D levels in different statin subtypes. ${ }^{[19,20]}$ Wilczek et al. indicated that serum $25(\mathrm{OH}) \mathrm{D}$ levels are rising after 3 months of lovastatin 20-80 mg/day usage. ${ }^{[21]}$ Likewise, simvastatin escalates levels of plasma Vitamin D metabolites and 1,25(OH)2D3 significantly. ${ }^{[22]}$

On the other hand, there are some studies displaying no association between statins and Vitamin D in the literature. Pravastatin was found not to be not affecting Vitamin D production in a research conducted on patients who took daily 10-80 mg pravastatin and was exposed to ultraviolet B light for 3 months. ${ }^{[16]}$ Furthermore, two other studies could not demonstrate a difference in Vitamin D levels between patients who were taking pravastatin $20 \mathrm{mg}$ /day and $40-80 \mathrm{mg}$ /day for 24 and 8 weeks, respectively. ${ }^{[17,23]}$

Meanwhile, analysis about the effect of statin usage duration on Vitamin D levels revealed that Vitamin D levels were significantly lower in the control group than short- and medium-term statin users in our study. Pérez-Castrillón et al. also demonstrated similar findings in their study conducted in 2007. ${ }^{[14]}$ Patients who had coronary artery disease and Vitamin D deficiency were given $10-80 \mathrm{mg}$ /day atorvastatin for 12 months, and at the end, mean Vitamin D levels were raised to $18.8 \pm 7.6 \mathrm{ng} / \mathrm{mL}$ from $16.4 \pm 7.6(P=0.003)$. ${ }^{[24]}$ The ratio of patients with Vitamin D deficiency was diminished to $57 \%$ after 12 months of statin treatment. ${ }^{[14]}$ The mechanism of the ability of statins to raise Vitamin D levels is not completely understood yet. While statins decrease both 7-DHC and cholesterol production, Vitamin D levels are expected to deescalate; however, no study has shown a drop in Vitamin D levels in statin users. ${ }^{[2]}$ According to the hypothesis of Grimes, there is a striking similarity between benefit of Vitamin D and statins which may be related with the activation of Vitamin D receptors by statins. ${ }^{[24]}$ Other researchers have also suggested plenty of potential mechanisms about this unexpected rise in Vitamin D with statins. ${ }^{[12,25,26]}$ First, Vitamin $\mathrm{D}$ is metabolized in liver and intestines by CYP3A4, and statins are also metabolized by CYP3A4. ${ }^{[25]}$ The competition in this common pathway might be associated with increased Vitamin D levels in patients on statin treatment. ${ }^{[25]}$ Second, 3-hydroxy-3-methylglutaryl-CoA (HmG-CoA) reductase inhibition by statins may be increasing 7-DHC levels in skin which is essential for $25(\mathrm{OH}) \mathrm{D}$ synthesis. ${ }^{[12]}$ This increment can explain bone mineral density increase and bone fracture decrease in statin users. ${ }^{[12]}$ A research related with this view was done by Aloia et al. ${ }^{[26]}$ They demonstrated higher Vitamin $\mathrm{D}$ levels in patients taking statins than who were not on statin treatment (20.51 \pm 8.05 vs. $17.31 \pm 7.21 \mathrm{ng} / \mathrm{mL}$, respectively) $(P<0.008)$ in a study aimed to show the benefits of Vitamin D3 on bone calcium levels conducted on postmenopausal African American women. ${ }^{[26]}$

The main limitations of our study are its single-centered basis and relatively low number of patients. Besides, as this was a cross-sectional study, we did not know initial Vitamin D levels before statin usage; hence, we could not evaluate the rise in Vitamin D levels with statins.

\section{Conclusion}

Advances in therapeutic methods led to longer life span, so increased number of patients with CVD and on statins is inevitable. Hence, the effects of statins besides cardiovascular ones will continue to interest researchers. Although our study aligned higher Vitamin D levels in statin users, large scale comprehensive studies are needed to validate these results.

\section{Financial support and sponsorship}

Nil.

\section{Conflicts of interest}

There are no conflicts of interest.

\section{RefEREnCES}

1. Taylor F, Ward K, Moore TH, Burke M, Davey Smith G, Casas JP, et al. Statins for the primary prevention of cardiovascular disease. Cochrane Database Syst Rev 2011;19:CD004816.

2. Reiner Ž. Statins in the primary prevention of cardiovascular disease. Nat Rev Cardiol 2013;10:453-64.

3. Kowalski J, Barylski M, Banach M, Grycewicz J, Irzmański R, Pawlicki L. Neutrophil superoxide anion generation during atorvastatin and fluvastatin therapy used in coronary heart disease primary prevention. J Cardiovasc Pharmacol 2006;48:143-7.

4. Athyros VG, Katsiki N, Tziomalos K, Gossios TD, Theocharidou E, Gkaliagkousi E, et al. Statins and cardiovascular outcomes in elderly and younger patients with coronary artery disease: A post hoc analysis of the GREACE study. Arch Med Sci 2013;9:418-26.

5. Barylski M, Nikfar S, Mikhailidis DP, Toth PP, Salari P, Ray KK, et al. Statins decrease all-cause mortality only in CKD patients not requiring dialysis therapy - A meta-analysis of 11 randomized controlled trials involving 21,295 participants. Pharmacol Res 2013;72:35-44.

6. Lai HM, Aronow WS, Mercando AD, Kalen P, Desai HV, Gandhi K, et al. The impact of statin therapy on long-term cardiovascular outcomes in an outpatient cardiology practice. Arch Med Sci 2012;8:53-6.

7. Sheng X, Murphy MJ, MacDonald TM, Wei L. Effect of statins on total 
cholesterol concentrations and cardiovascular outcomes in patients with diabetes mellitus: A population-based cohort study. Eur J Clin Pharmacol 2012;68:1201-8.

8. Aboa-Eboulé C, Binquet C, Jacquin A, Hervieu M, Bonithon-Kopp C, Durier J, et al. Effect of previous statin therapy on severity and outcome in ischemic stroke patients: A population-based study. J Neurol 2013;260:30-7.

9. Szadkowska I, Stanczyk A, Aronow WS, Kowalski J, Pawlicki L, Ahmed A, et al. Statin therapy in the elderly: A review. Arch Gerontol Geriatr 2010;50:114-8.

10. Rizzo M, Nikolic D, Banach M, Montalto G. Statin treatment in the elderly: How much do we know? Arch Med Sci 2013;9:585-8.

11. Stone NJ, Robinson JG, Lichtenstein AH, Bairey Merz CN, Blum CB, Eckel RH, et al. 2013 ACC/AHA guideline on the treatment of blood cholesterol to reduce atherosclerotic cardiovascular risk in adults: A report of the American College of Cardiology/American Heart Association task force on practice guidelines. J Am Coll Cardiol 2014;63:2889-934.

12. Guryev O, Carvalho RA, Usanov S, Gilep A, Estabrook RW. A pathway for the metabolism of Vitamin D3: Unique hydroxylated metabolites formed during catalysis with cytochrome P450scc (CYP11A1). Proc Natl Acad Sci U S A 2003;100:14754-9.

13. Yavuz B, Ertugrul DT, Cil H, Ata N, Akin KO, Yalcin AA, et al. Increased levels of 25 hydroxyvitamin D and 1,25-dihydroxyvitamin D after rosuvastatin treatment: A novel pleiotropic effect of statins? Cardiovasc Drugs Ther 2009;23:295-9.

14. Pérez-Castrillón JL, Vega G, Abad L, Sanz A, Chaves J, Hernandez G, et al. Effects of atorvastatin on Vitamin D levels in patients with acute ischemic heart disease. Am J Cardiol 2007;99:903-5.

15. Rejnmark L, Buus NH, Vestergaard P, Heickendorff L, Andreasen F, Larsen ML, et al. Effects of simvastatin on bone turnover and BMD: A 1-year randomized controlled trial in postmenopausal osteopenic women. J Bone Miner Res 2004;19:737-44.

16. Dobs AS, Levine MA, Margolis S. Effects of pravastatin, a new
HMG-CoA reductase inhibitor, on Vitamin D synthesis in man. Metabolism 1991;40:524-8.

17. Ismail F, Corder CN, Epstein S, Barbi G, Thomas S. Effects of pravastatin and cholestyramine on circulating levels of parathyroid hormone and Vitamin D metabolites. Clin Ther 1990;12:427-30.

18. Ertugrul DT, Yavuz B, Cil H, Ata N, Akin KO, Kucukazman M, et al STATIN-D study: Comparison of the influences of rosuvastatin and fluvastatin treatment on the levels of 25 hydroxyvitamin D. Cardiovasc Ther 2011;29:146-52.

19. Bischoff-Ferrari HA, Fischer K, Orav EJ, Dawson-Hughes B, Meyer U, Chocano-Bedoya PO, et al. Statin use and 25-hydroxyvitamin D blood level response to Vitamin D treatment of older adults. J Am Geriatr Soc 2017;65:1267-73.

20. Sahebkar A, Reiner Z, Simental-Mendia LE, Ferretti G, Della Corte C, Nobili V. Impact of statin therapy on plasma Vitamin D levels: A systematic review and meta-analysis. Curr Pharm Des 2017;23:861-9.

21. Wilczek H, Sobra J, Justová V, Ceska R, Jůzová Z, Procházková R, et al. Iatropathogenic effect of mevacor on Vitamin D metabolism. Cas Lek Cesk 1989;128:1254-6.

22. Wilczek H, Sobra J, Ceska R, Justová V, Jůzová Z, Procházková R, et al. Monitoring plasma levels of Vitamin D metabolites in simvastatin (Zocor) therapy in patients with familial hypercholesterolemia. Cas Lek Cesk 1994;133:727-9.

23. Montagnani M, Loré F, Di Cairano G, Gonnelli S, Ciuoli C, Montagnani A, et al. Effects of pravastatin treatment on Vitamin D metabolites. Clin Ther 1994;16:824-9.

24. Grimes DS. Are statins analogues of Vitamin D? Lancet 2006;368:83-6.

25. Xu Y, Hashizume T, Shuhart MC, Davis CL, Nelson WL, Sakaki T, et al. Intestinal and hepatic CYP3A4 catalyze hydroxylation of 1alpha, 25-dihydroxyvitamin $\mathrm{D}(3)$ : Implications for drug-induced osteomalacia. Mol Pharmacol 2006;69:56-65.

26. Aloia JF, Li-Ng M, Pollack S. Statins and Vitamin D. Am J Cardiol 2007;100:1329. 